\title{
The Lolium Pathotype of Magnaporthe oryzae Recovered from a Single Blasted Wheat Plant in the United States
}

\author{
Mark Farman, Department of Plant Pathology, University of Kentucky, Lexington 40546; Gary Peterson, United States Department of \\ Agriculture-Agricultural Research Service (USDA-ARS), Foreign Disease-Weed Science Research Unit, Fort Detrick, MD 21702; \\ Li Chen and John Starnes, Department of Plant Pathology, University of Kentucky; Barbara Valent, Department of Plant Pathology, \\ Kansas State University, Manhattan 66506; Paul Bachi, Department of Plant Pathology, University of Kentucky; and University of Kentucky \\ Research and Education Center, Princeton 42445; Lloyd Murdock, University of Kentucky Research and Education Center, Princeton; \\ Don Hershman, Department of Plant Pathology, University of Kentucky; and University of Kentucky Research and Education Center, \\ Princeton; Kerry Pedley, USDA-ARS, Fort Detrick; and J. Mauricio Fernandes and Jorge Bavaresco, Embrapa Wheat, Passo Fundo, \\ RS, 99001-970, Brazil
}

\begin{abstract}
Wheat blast is a devastating disease that was first identified in Brazil and has subsequently spread to surrounding countries in South America. In May 2011, disease scouting in a University of Kentucky wheat trial plot in Princeton, KY identified a single plant with disease symptoms that differed from the Fusarium head blight that was present in surrounding wheat. The plant in question bore a single diseased head that was bleached yellow from a point about one-third up the rachis to the tip. A gray mycelial mass was observed at the boundary of the healthy tissue and microscopic examination of this material revealed pyriform spores consistent with a Magnaporthe sp. The pathogen was subsequently identified as Magnaporthe oryzae through amplification and sequencing of molecular markers, and genome sequencing

revealed that the U.S. wheat blast isolate was most closely related to an $M$. oryzae strain isolated from annual ryegrass in 2002 and quite distantly related to M. oryzae strains causing wheat blast in South America. The suspect isolate was pathogenic to wheat, as indicated by growth chamber inoculation tests. We conclude that this first occurrence of wheat blast in the United States was most likely caused by a strain that evolved from an endemic Lolium-infecting pathogen and not by an exotic introduction from South America. Moreover, we show that $M$. oryzae strains capable of infecting wheat have existed in the United States for at least 16 years. Finally, evidence is presented that the environmental conditions in Princeton during the spring of 2011 were unusually conducive to the early production of blast inoculum.
\end{abstract}

Though best known as the rice blast fungus, Magnaporthe oryzae B. C. Couch (anamorph Pyricularia oryzae) causes diseases on a wide variety of graminaceous species, including other cereal crops such as wheat and barley, forage species such as annual ryegrass and

Present address of J. Starnes: Somerset Community College, 808 Monticello St., Somerset, KY 42501.

Corresponding author: M. Farman; E-mail: farman@uky.edu

This is contribution number 16-151-J from the Kansas Agricultural Experiment Station and contribution number 15-12-124 from the Kentucky Agricultural Experiment Station, and is published with the approval of the respective station directors.

The U.S. Department of Agriculture (USDA) prohibits discrimination in all its programs and activities on the basis of race, color, national origin, age, disability, and where applicable, sex, marital status, familial status, parental status, religion, sexual orientation, genetic information, political beliefs, reprisal, or because all or part of an individual's income is derived from any public assistance program. (Not all prohibited bases apply to all programs.) Persons with disabilities who require alternative means for communication of program information (Braille, large print, audiotape, etc.) should contact USDA's TARGET Center at (202) 720-2600 (voice and TDD). To file a complaint of discrimination, write to USDA, Director, Office of Civil Rights, $1400 \mathrm{In}-$ dependence Avenue, S.W., Washington, D.C. 20250-9410, or call (800) $795-3272$ (voice) or (202) 720-6382 (TDD). USDA is an equal opportunity provider and employer. Mention of trade names or commercial products in this publication is solely for the purpose of providing specific information and does not imply recommendation or endorsement by the U.S. Department of Agriculture.

*The $\boldsymbol{e}$-Xtra logo stands for "electronic extra" and indicates that three supplementary figures are published online.

Accepted for publication 12 December 2016.

This article is in the public domain and not copyrightable. It may be freely reprinted with customary crediting of the source. The American Phytopathological Society, 2017. tall fescue, and turfgrasses that include perennial ryegrass (Lolium perenne) and St. Augustinegrass (Stenotaphrum secundatum) (Ou 1985). Wheat blast is a relatively new disease that was first identified in 1985 in the Brazilian state of Parana (Igarashi et al. 1986) and has now spread to other wheat-growing regions within South America (Dos Anjos et al. 1996; Goulart and Paiva 2000; Goulart et al. 1990; Igarashi 1990; Maciel et al. 2014; Picinini and Fernandes 1990) and, more recently, to Asia (Malaker et al. 2016). The wheat blast pathogen can infect all aboveground plant parts (Igarashi 1990) but the most visible and devastating symptoms occur when the head is colonized. Although the fungus can infect the glumes and awns, colonization of the rachis is the most damaging because it causes bleaching of the entire head distal to the point of infection and prevents further seed development. If disease occurs during head emergence, it can result in complete sterility of the spike (Igarashi 1990; Igarashi et al. 1986). Head bleaching often occurs in the absence of leaf symptoms (Cruz et al. 2012; Kohli et al. 2011; Urashima et al. 2009) and, in such instances, it is the first indication of fungal infection. Thus, unfortunately, by the time bleaching is observed, it is too late to employ curative measures, and losses from 10 to $100 \%$ percent can be incurred (Goulart and Paiva 2000; Goulart et al. 1992; Kohli et al. 2011).

For a few years after its emergence, wheat blast was restricted to Brazil. However, more recently, it has spread to neighboring countries, including Bolivia (Barea and Toledo 1996), Paraguay (Viedma 2005) and Argentina (Cabrera and Gutiérrez 2007). Until 2011, however, wheat blast had not been detected outside of South America. In May 2011, while scouting for Fusarium head blight (FHB) in a University of Kentucky wheat trial in Princeton, KY, a single plant was identified that exhibited a head disease symptom that was different from FHB. Here we report the formal identification of the causal organism as $M$. oryzae and we describe a pathological and molecular characterization of the disease-causing isolate that was performed to determine whether the infection was caused by a wheat blast strain that had been introduced from South America, or was an endemic strain that had "jumped host."

\section{Materials and Methods}

Establishment of a pure culture of the Kentucky wheat blast isolate. Under the stereomicroscope, fungal mycelium was clearly 
visible at the border of the healthy and diseased rachis. A Pasteur pipette was sealed and sterilized in a Bunsen burner flame and, once cooled, was gently massaged over the mycelial and spore mass. The pipette was then streaked across $4 \%$ water agar supplemented with ampicillin at $100 \mu \mathrm{g} / \mathrm{ml}$. After overnight incubation at room temperature, germinated conidia were observed under the stereomicroscope and 20 individual conidia with visible germ tubes were picked and placed on fresh oatmeal agar (OMA) plates supplemented with ampicillin at $100 \mu \mathrm{g} / \mathrm{ml}$. Sterile Whatman 3M paper disks were placed on the surface of the agar and the cultures were incubated at room temperature under constant white light illumination until they had grown across the paper. The paper disks were subsequently collected, placed in glassine envelopes, dried in the biosafety hood, and sent to the United States Department of Agriculture-Agricultural Research Service (USDA-ARS) Animal and Plant Health Inspection Service lab in Beltsville, MD for permanent storage; and, from there, to the USDA-ARS Foreign Disease-Weed Science Research Unit at Fort Detrick, MD for pathogenicity testing.
Other fungal strains. Strains used in this study are listed in Table 1. All strains whose genomes were sequenced at the University of Kentucky and Kansas State University were single-spore purified on $4 \%$ water agar plus ampicillin prior to DNA isolation (see above). Routine plate culturing was performed using OMA and liquid cultures were established in complete medium (Valent et al. 1986).

Genomic DNA extraction. Single-spore cultures were placed in tubes containing $10 \mathrm{ml}$ of complete medium broth. The cultures were then grown for 7 days at room temperature with constant shaking (approximately $250 \mathrm{rpm}$ ) under ambient light. The mycelial balls were blotted dry on paper towels, placed in 15-ml plastic tubes, and freeze dried for $24 \mathrm{~h}$. The dried mycelium was crushed to a powder by rolling a clean glass rod around the inside wall of the tube. The resulting powder was suspended in $1.5 \mathrm{ml}$ of lysis buffer and then placed in a $65^{\circ} \mathrm{C}$ water bath for $15 \mathrm{~min}$. Phenol/chloroform/isoamyl alcohol $(1 \mathrm{ml})$ was added and mixed in thoroughly by flicking the tube a few times. The suspension was placed back in the $65^{\circ} \mathrm{C}$ water bath for $30 \mathrm{~min}$, with the tube being inverted several times after $15 \mathrm{~min}$

Table 1. Magnaporthe oryzae strains used in this study

\begin{tabular}{|c|c|c|c|c|}
\hline Isolate & Host species & Year $^{\mathbf{a}}$ & Place of isolation & Source, reference \\
\hline WBKY11-15 & Triticum aestivum & 2011 & Princeton, KY & L. Murdock \\
\hline $\mathrm{Br} 2$ & T. aestivum & 1990 & Parana, Brazil & A. Urashima (Urashima et al. 1999) \\
\hline Br5 & T. aestivum & 1990 & Parana, Brazil & A. Urashima (Urashima et al. 1999) \\
\hline Br6 & T. aestivum & 1990 & Parana, Brazil & A. Urashima (Urashima et al. 1999) \\
\hline $\mathrm{Br} 7$ & T. aestivum & 1990 & Parana, Brazil & A. Urashima (Urashima et al. 1999) \\
\hline Br39 & T. aestivum & 1990 & Parana, Brazil & A. Urashima (Urashima et al. 1999) \\
\hline $\mathrm{Br} 48$ & T. aestivum & 1990 & Mato Grosso do Sul, Brazil & A. Urashima (Urashima et al. 1999) \\
\hline $\mathrm{Br} 49$ & T. aestivum & 1990 & Mato Grosso do Sul, Brazil & A. Urashima (Urashima et al. 1999) \\
\hline $\mathrm{Br} 52$ & T. aestivum & 1990 & Mato Grosso do Sul, Brazil & A. Urashima (Urashima et al. 1999) \\
\hline Br80 & T. aestivum & 1991 & Brazil & D. Tharreau \\
\hline Br113.1C & T. aestivum & 1992 & Parana, Brazil & A. Urashima (Urashima et al. 1999) \\
\hline Br115.7 & T. aestivum & 1992 & Parana, Brazil & A. Urashima (Urashima et al. 1999) \\
\hline Br115.12 & T. aestivum & 1992 & Paraña, Brazil & A. Urashima (Urashima et al. 1999) \\
\hline Br117.1F & T. aestivum & 1992 & Paraña, Brazil & A. Urashima (Urashima et al. 1999) \\
\hline Br119.1F & T. aestivum & 1992 & Paraña, Brazil & A. Urashima (Urashima et al. 1999) \\
\hline $\mathrm{Br} 123.1 \mathrm{H}$ & T. aestivum & 1992 & Paraña, Brazil & A. Urashima (Urashima et al. 1999) \\
\hline Br128.1E & T. aestivum & 1992 & Paraña, Brazil & A. Urashima (Urashima et al. 1999) \\
\hline Br130 & T. aestivum & NA & Brazil & T. Mitchell \\
\hline Br131.2 & T. aestivum & 1992 & Parana, Brazil & A. Urashima (Urashima et al. 1999) \\
\hline Br202.1B & T. aestivum & 1992 & Mato Grosso do Sul, Brazil & A. Urashima (Urashima et al. 1999) \\
\hline $\mathrm{Br} 213.1 \mathrm{~B}$ & T. aestivum & 1992 & Mato Grosso do Sul, Brazil & A. Urashima (Urashima et al. 1999) \\
\hline B2 & T. aestivum & 2011 & Bolivia & C. Cruz \\
\hline $\mathrm{T} 25$ & T. aestivum & 1988 & Paraña, Brazil & S. Igarashi (Cruz et al. 2012) \\
\hline WBSS & T. aestivum & NA & Brazil & A. Urashima \\
\hline WHTQ & T. aestivum & NA & Brazil & T. Mitchell \\
\hline PL1-1 & Lolium multiflorum & 2001 & Pulaski County, KY & Vincelli et al. (2008) \\
\hline PL2-1 & L. multiflorum & 2001 & Pulaski County, KY & Vincelli et al. (2008) \\
\hline PL3-1 & L. multiflorum & 2001 & Pulaski County, KY & Vincelli et al. (2008) \\
\hline CHRF & L. perenne & 1996 & Silver Spring, MD & P. Dernoeden (Farman 2002) \\
\hline CHW & L. perenne & 1996 & Annapolis, MD & P. Dernoeden (Farman 2002) \\
\hline FH & L. perenne & 1996 & Hagerstown, MD & P. Dernoeden (Farman 2002) \\
\hline GG11 & L. perenne & 1997 & Lexington, KY & Farman $(2002)$ \\
\hline $\mathrm{HO}$ & L. perenne & 1996 & Richmond, PA & P. Dernoeden (Farman 2002) \\
\hline LpKY97-1 & L. perenne & 1997 & Lexington, KY & M. Farman (Farman 2002) \\
\hline PgPA33B-01 & L. perenne & 2001 & Pennsylvania & W. Uddin (Tosa et al. 2007) \\
\hline PgPA05T-01 & L. perenne & 2001 & Pennsylvania & W. Uddin (Tosa et al. 2007) \\
\hline PgPA33B-06 & L. perenne & 2006 & Pennsylvania & W. Uddin (Tosa et al. 2007) \\
\hline PgPA35H-4.1 & L. perenne & 2000 & Pennsylvania & W. Uddin (Tosa et al. 2007) \\
\hline Guy11 & Oryza sativa & 1988 & French Guyana & Leung et al. (1988) \\
\hline P131 & O. sativa & NA & Japan & Xue et al. (2012) \\
\hline Y34 & O. sativa & 1982 & Yunnan, China & Xue et al. (2012) \\
\hline B51 & Eleusine indica & 2012 & Quirusillas, Bolivia & J. Stack/C. Cruz \\
\hline UFO822 & Stenotaphrum secundatum & 1982 & Florida & L. Datnoff \\
\hline Arcadia & Setaria italica & 2001 & Lexington, KY & Farman (2002) \\
\hline S-4 & S. italica & 2013 & Unionville, MD & G. Peterson \\
\hline $60-3$ & Lab strain ${ }^{b}$ & 2003 & $\ldots$ & M. Farman \\
\hline
\end{tabular}

${ }^{\mathrm{a}} \mathrm{NA}=$ not available.

${ }^{b}$ Progeny isolate from the cross $\mathrm{FH} \times 2539$ (Starnes et al. 2012). 
to resuspend the mycelial slurry. The tube was subsequently centrifuged for $20 \mathrm{~min}$ at $3,716 \times g$ in a benchtop centrifuge (Sorvall Legend RT+; Thermo Scientific, Waltham, MA), after which the aqueous layer (approximately $1.2 \mathrm{ml}$ ) was carefully pipetted into a microfuge tube. The DNA was precipitated by adding 0.54 volumes of isopropanol. After mixing thoroughly by inverting the tube several times, the DNA was pelleted by centrifuging for $10 \mathrm{~min}$ at $14,000 \times g$ in a benchtop microfuge (Beckman Coulter, Inc., Indianapolis, IN). After discarding the supernatant, the DNA was rinsed with $70 \%$ ethanol and then air dried on the benchtop. Finally, the pellet was dissolved in $100 \mu \mathrm{l}$ of Tris-EDTA (TE) buffer containing RNase A $(10 \mu \mathrm{g} / \mathrm{ml})$.

Mycelial or conidial polymerase chain reaction. To enable a rapid molecular diagnosis, DNA was released directly from infected glume material by removing the diseased tissue with sterilized forceps and submerging in $500 \mu \mathrm{l}$ of TE buffer. The tube was then placed in a boiling water bath for $10 \mathrm{~min}$ to burst the hyphae or conidia and release the DNA. After cooling, $1 \mu$ l of the supernatant was used as a template for polymerase chain reaction (PCR). Amplification was performed using ExTaq polymerase with the supplied nucleotides and buffers, according to the manufacturer's specifications (Clontech, Mountain View, CA). Amplification conditions were as follows: denaturation at $95^{\circ} \mathrm{C}$ for $2 \mathrm{~min}$; followed by 35 cycles of $95^{\circ} \mathrm{C}$ for $30 \mathrm{~s}, 54^{\circ} \mathrm{C}$ for $30 \mathrm{~s}$, and $72^{\circ} \mathrm{C}$ for $1 \mathrm{~min}$; followed by a final extension phase at $72^{\circ} \mathrm{C}$ for $5 \mathrm{~min}$. Primer sequences $\left(5^{\prime}\right.$ to $\left.3^{\prime}\right)$ were as follows: MoTeR1_RT_F: CGTTAAAAGACCAGCACGAC,MoTeR1_RT_R: TCCCGGCCAATAGACGAA, CH7BAC7_F: AAGACACGAGAG CAAAGAAAGAAG，CH7BAC7_R: CGATACATTACAGTGCC TACGAA, MPG1_F: AGAAGGTCGTCTCTTGCTGC, and MPG1_R: TTCACTCAACGCTGATCGC.

Genome sequencing. Genome sequences for strains WBKY1115, FH, LpKY97-1, and PL3-1 were acquired on Roche 454 GS FLX machines (Roche Diagnostics, Indianapolis, IN) at the University of Kentucky and Kansas State University. For shotgun library preparation, approximately $1 \mu \mathrm{g}$ of genomic DNA was sheared for 1 min with nitrogen at 15 psi using a Roche Diagnostics nebulizer. The libraries were generated according to the Rapid Library preparation method specified by the manufacturer. Paired-end sequencing was used to supplement the shotgun sequences for LpKY97-1 and WBKY11-15 (one plate of paired-end reads per genome). For paired-end libraries, the DNA was sheared on a Hydroshear machine (GeneMachines, San Carlos, CA) using 20 cycles at speed setting 12 (3-kb paired ends) or 16 (8-kb paired ends). The 3-kb fragments were recovered using AMPure size exclusion beads (Beckman Coulter Inc.), whereas the 8-kb fragments were fractionated on a $0.5 \%$ "Megabase" agarose gel (Bio-Rad, Hercules, CA) in Tris-acetate-EDTA buffer and recovered using EluTrap electroelution (Whatman Inc., Florham, NJ.). The 3-kb paired-end library was prepared according to the GS FLX Titanium 3-kb Span Paired End Library Preparation Manual (Roche Diagnostics) and the 8-kb paired-end library was prepared according to the GS FLX Titanium 20-kb and 8-kb Span Paired End Library preparation method.

Genome sequences for Guy11, Arcadia, and PH42 were acquired from paired-end reads that were generated using the Illumina Miseq machine. The libraries were generated using the Nextera kit (Illumina, San Diego, CA), following the supplied protocols. Genome sequences for BR130 and WHTQ were kindly provided by Thomas Mitchell (The Ohio State University) and the WBSS sequence was provided by Nicholas Talbot (University of Exeter). Sequences for the rice pathogens P131 (JH794034.1) and Y34 (JH792835.1) were downloaded from GenBank.

Genomes were assembled using Newbler 2.6 on the iPlant server (Goff et al. 2011) or a local installation of Newbler (2.9). Scaffolds and unscaffolded contigs greater than $200 \mathrm{bp}$ in length were subsequently combined to create "merged" assemblies.

Whole-genome analysis of single-nucleotide polymorphisms. First, self-by-self blast searches were used to identify all sequences that occurred more than once per genome, and these segments were then masked. Next, reciprocal pairwise BLAST searches were performed in all possible combinations, with each masked genome being used as both query and subject sequence. Pertinent BLAST parameters were a maximum e-value of 1e-100, dust filtering off, and -max_target_seqs set to
20,000. A custom Perl script was then used to tally numbers of single-nucleotide polymorphisms (SNPs) between each isolate pair. To avoid errant SNP calling in repeated chromosome segments, the results were filtered to ignore mismatches in paralogous regions that were not identified by self-BLAST but were uncovered in the pairwise comparisons. Insertion/deletion polymorphisms (indels) were not counted because several of the genome sequences were acquired using Roche 454 pyrosequencing technology, which is known to generate indels through errant base calling (Gilles et al. 2011). Due to the way BLAST calculates e-values, reciprocal blasts involving the same isolate pair usually yield slightly different SNP numbers. Therefore, we report the genetic distances as averages of the two values. To account for major differences in genomic content and sequence composition, pairwise distances were normalized by representing them as SNPs per megabase of uniquely alignable sequence.

Plant inoculations. Inoculations were performed under Federal and State permits within the USDA-ARS biosafety level-3 plant disease containment facility at Fort Detrick, MD (Melching et al. 1983). Hard red spring wheat 'Cavalier' was used as a susceptible host. Soil mix consisted of $0.18 \mathrm{~m}^{3}$ peat, $0.11 \mathrm{~m}^{3}$ vermiculite, $0.03 \mathrm{~m}^{3}$ perlite, 1.06 liter of wetting agent, $2.4 \mathrm{~kg}$ of Osmocote 14-14-14, $2.3 \mathrm{~kg}$ of lime, $144 \mathrm{~kg}$ of soil, and $171 \mathrm{of} \mathrm{kg}$ sand. Seed were planted in $6-\mathrm{cm}$ clay pots at 4 seeds/pot and maintained in a greenhouse (average $25.8^{\circ} \mathrm{C}$ ), supplementing natural light conditions with $1,000-\mathrm{W}$ metal halide lamps $\left(28 \mu \mathrm{mol} / \mathrm{m}^{2} / \mathrm{s}\right)$ to maintain $16 \mathrm{~h}$ of light per day. At the onset of spike emergence (Zadoks growth stage [GS]-59), plants were transported to the USDA-ARS biosafety level-3 plant disease containment facility at Frederick, MD, where they were inoculated and grown in a containment greenhouse at $25( \pm 4)^{\circ} \mathrm{C}$ until rated. Supplemental 1,000 -watt metal halide lights $\left(28 \mu \mathrm{mol} / \mathrm{m}^{2} / \mathrm{s}\right)$ were used to extend the day length to $16 \mathrm{~h}$.

A monoconidial isolate of the $M$. oryzae strain isolated from the wheat head in Kentucky (WBKY11-15) and Triticum isolate T25, collected in 1988 in Parana, Brazil were grown on OMA plates for 12 days on a lab bench under continuous fluorescent light (33 $\left.\mu \mathrm{mol} / \mathrm{m}^{2} / \mathrm{s}\right)$. Cultures were flooded with sterile water with $0.01 \%$ Tween-20 and gently scraped using a $1.3-\mathrm{cm}$ flat, soft nylon paint brush to dislodge the conidia, and the spore suspension was filtered through a $53-\mu \mathrm{m}$ pore-size sieve. For each isolate, inoculum was diluted to $1 \times 10^{3}, 5 \times 10^{3}, 1 \times 10^{4}$, and $1 \times 10^{5}$ conidia/ml. Controls were inoculated with just $0.01 \%$ Tween-20. For each isolate or concentration, 12 newly emerged spikes (Zadoks GS-59) of Cavalier wheat were spray inoculated with an atomizer (Devilbliss Manufacturing Co., Toledo, $\mathrm{OH}$ ) at $69 \mathrm{kPa}$. Individual heads were covered with a clear, 7.5-by-13-cm bag with a zipper closure (Uline, Coppell, TX) and placed in a shaded portion of the greenhouse. Bags were removed $24 \mathrm{~h}$ after inoculation, and plants were moved to a greenhouse bench. The greenhouse temperature was $25( \pm 4)^{\circ} \mathrm{C}$ and supplemental high-pressure sodium lighting was used to extend the day length to $16 \mathrm{~h}$. Plants were rated 14 to 16 days after inoculation, based on the percentage of blasted florets per head. For the purpose of analysis, each individual spike was considered a replication. Analysis of variance (StatPlus.mac v5; Analystsoft, Inc., Walnut, CA) (http://www.analystsoft.com/en/) was performed to compare wheat spike infection by the isolates originally from nonwheat hosts, with isolates of the Triticum pathotype.

In a second study, 11 Magnaporthe isolates originating from Triticum aestivum, L. perenne, L. multiflorum, and Setaria spp. were each used to inoculate nine Cavalier wheat spikes as described above, spraying a suspension of $5 \times 10^{4}$ conidia/ml until run-off (approximately $1 \mathrm{ml} / \mathrm{spike}$ ). Data collected were the average percentage of infected florets per spike. After evaluation, inoculated spikes were transferred to culture dishes containing $2 \%$ water agar and monitored with a stereomicroscope for evidence of sporulation. When disease was observed, the pathogen was reisolated on OMA plates. Analysis of variance was performed to compare wheat spike infection by the isolates originally from nonwheat hosts with isolates of the Triticum pathotype.

Weather-based modeling of wheat blast for Western Kentucky. A wheat blast predictive model (Bavaresco et al. 2015) (https://github. $\mathrm{com} / \mathrm{jlbavaresco/brusoneModel)} \mathrm{was} \mathrm{adapted} \mathrm{from} \mathrm{prior} \mathrm{work} \mathrm{on} \mathrm{rice}$ 
blast disease (Arai and Yoshino 1987; Kim 2000). It uses hourly weather data to calculate numbers of hours that are conducive to spore production and provides an estimate of inoculum potential. Hourly weather data (temperature, relative humidity, and rainfall) were obtained from the Kentucky Mesonet (http://www.kymesonet.org) and Midwest Regional Climate Center (http://mrcc.isws.illinois.edu). Data were retrieved for Caldwell County, the location of the University of Kentucky Research and Education Center (UKREC), and for the surrounding counties for which data were available. In most cases, the necessary data archives went back only as far as 2008. Cumulative hours conducive to conidium production were then plotted against time and the model was used to estimate inoculum potential at heading time.

\section{Results}

Classical disease diagnostics indicated that the suspect isolate belongs to the genus Magnaporthe. The diseased head found at the UKREC lacked the typical pinkish tinge characteristic of sporulation by the FHB fungus. Instead, the top two-thirds of the head was bleached white (Fig. 1A). Removal of a number of kernels around the point of transition uncovered a mass of gray mycelium (Fig. 1B). A small quantity of this mycelium was transferred to a slide for microscopic visualization. This revealed the pyriform spores characteristic of Magnaporthe spp. (Fig. 1C).

PCR-based molecular markers identified the suspect isolate as M. oryzae. Given that M. oryzae is known to cause blast on wheat in South America, we considered it most likely that the causal pathogen belonged to this species. To confirm this suspicion, the diseased head was delivered to the University of Kentucky so that a PCR-based diagnostic assay could be performed to (i) confirm that the causal organism was $M$. oryzae and (ii) establish whether the pathogen was genetically similar to wheat blast isolates from Brazil and, as such, a possible exotic introduction. M. oryzae strains from wheat are most closely related to strains from Lolium spp. (Farman 2002). Therefore, among the three M. oryzae-specific markers that were utilized, we included two that were predicted to differentiate between the Triticum (MoT) and Lolium (MoL) pathotypes. The first marker, MoTeR1_RT, is a fragment from the MoTeR1 reverse-transcription (RT) gene which, to date, has been found only in M. oryzae isolates from wheat, Lolium spp., and Eleusine spp. Interrogation of GenBank entries for the sequence-based markers CH7BAC7 and MPG1 utilized by (Couch et al. 2005) indicated that they had the potential to distinguish between strains from wheat and Lolium spp.; therefore, these latter markers were included to provide a clue as to the origin of the suspect isolate.
The MoTeR1_RT primers amplified a product of the expected size from DNA of the suspect strain. Also amplified were the single-copy CH7BAC7 and MPG1 markers. In each case, equivalent products were amplified from the positive control isolate 60-3 but not from the "no-template" control reactions (Fig. 2). The successful amplification of the three markers provided a strong indication that the pathogen was, indeed, $M$. oryzae. This was subsequently confirmed by amplicon sequencing.

The PCR-based markers were unable to resolve the origin of the suspect isolate. Sequencing of the PCR amplicons revealed that the suspect isolate possessed the wheat blast (MoT) allele for CH7BAC7 (Supplementary Fig. S1). Surprisingly, it possessed the MoL allele for MPG1 (Supplementary Fig. S2). These conflicting results raised a concern that the $\mathrm{CH7BAC7}$ or MPG1 might not be perfectly diagnostic for MoT and MoL. To test this possibility, sequencing and cleavable amplified polymorphic sequence analysis were used to survey $\mathrm{CH} 7 \mathrm{BAC} 7$ and MPG1 alleles among additional isolates from the MoT (18 isolates) and MoL populations (6 isolates).

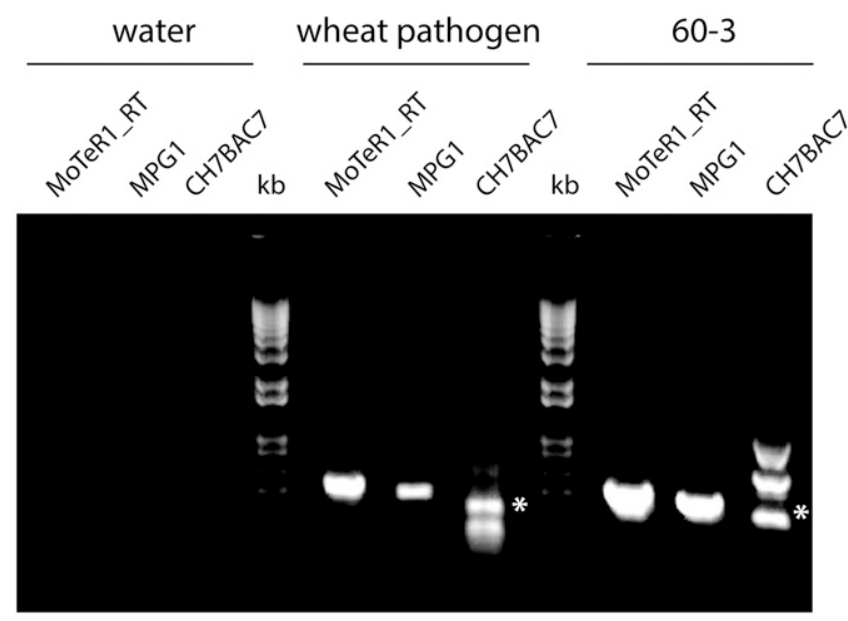

Fig. 2. Diagnostic polymerase chain reaction (PCR) test that confirmed the presence of Magnaporthe oryzae. Spore DNA from the suspect isolate was used as template for PCR using primers for MoTeR1_RT, CH7BAC7, and MPG1. The experiment included a no-DNA control and spore DNA from positive control isolate 60-3. CH7BAC7 yielded multiple amplicons; the correct products are indicated with asterisks.

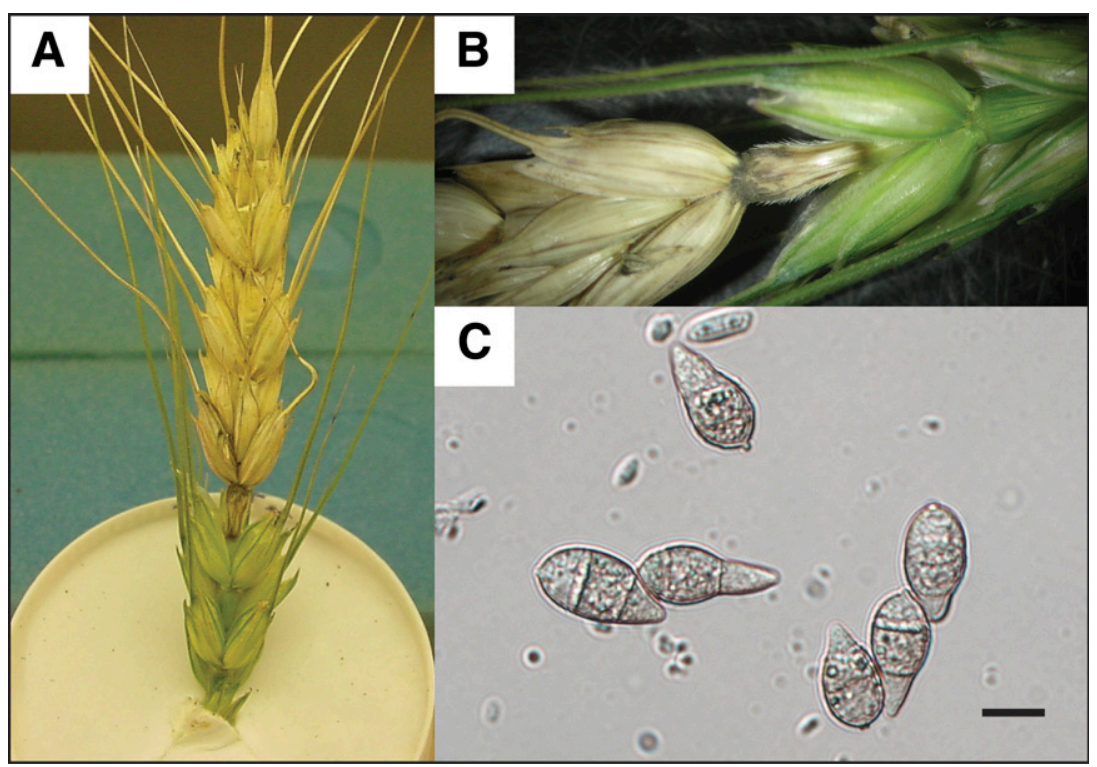

Fig. 1. Wheat blast identified in Princeton, KY, May 2011. A, Diseased wheat head exhibiting characteristic bleaching symptoms. B, Close-up of gray, sporulating mycelial mass. C, Pyriform spores released from the mycelium. Scale bar is $10 \mu \mathrm{m}$. 
This revealed that $\mathrm{CH} 7 \mathrm{BAC} 7$ genotyping was diagnostic because the MoL isolates possessed $\mathrm{CH} 7 \mathrm{BAC} 7^{\mathrm{MoL}}$ whereas all of the MoT isolates had CH7BAC7 ${ }^{\mathrm{MoT}}$ (data not shown). In contrast, however, MPG1 was not diagnostic because, although the MoL isolates all possessed MPG1 $1^{\mathrm{MoL}}$, this allele was also present in one of the 18 MoT isolates (Br123.1H; Supplementary Fig. S3). Interestingly, sequence analysis of selected wheat blast amplicons revealed a third MPG1 allele within the MoT population (strain Br80).

Genome sequencing identified the suspect isolate as an endemic strain. Rather than seeking additional markers to try and resolve the origin of the KY isolate, a genome sequence was acquired for a representative single-spore culture (WBKY11-15) as well as representative isolates from perennial ryegrass (FH and LpKY971), annual ryegrass (PL3-1), and a wheat blast isolate from Bolivia (B2). Genome sequences for three additional Brazilian wheat blast isolates (Br130, WBSS, and WHTQ) were kindly provided by collaborators. Sequences for the widely studied rice pathogen Guy11, and two publicly available rice blast genomes (P131 and Y34) were included as "external" references, as were genomes of isolates PH42 from finger millet (Eleusine corocana) and Arcadia from foxtail (Setaria viridis).
Masked genome sequences were aligned with one another in reciprocal, pairwise fashion and SNPs occurring in uniquely aligned regions were tallied. This revealed that WBKY11-15 was most closely related to PL3-1 (90 SNPs/Mb, or $0.009 \%$ sequence divergence; Table 2, bold). The next most closely related strains were the gray leaf spot pathogens from perennial ryegrass (Table 2 , italics). In contrast, WBKY1115 exhibited significant sequence divergence when compared with the South American wheat blast strains, with the most similar strain being BR130 (0.025\% divergence) (Table 2). Much higher sequence divergence was detected relative to the millet pathogen PH42, the foxtail pathogen Arcadia, as well the rice blast strains Guy11, P131, and Y34.

To provide a visual representation of the genetic relatedness among isolates, the pairwise genetic distances presented in Table 2 were used to construct a neighbor-joining tree. The resulting tree contained four distinct isolate groups (Fig. 3). WBKY11-15 and the isolate from annual ryegrass formed a discrete group, as did the perennial ryegrass pathogens. The most closely related outgroup to the wheat blast and Lolium clades was represented by the millet pathogen PH42. However, the distance to this outgroup was quite large. The wheat blast and gray leaf spot pathogens were very distinct from the isolates infecting foxtail and rice.

Table 2. Pairwise genetic distances between the Kentucky wheat blast isolate and select Magnaporthe strains $^{\mathrm{a}}$

\begin{tabular}{|c|c|c|c|c|c|c|c|c|c|c|c|c|}
\hline Strains & B2 & BR130 & WHTQ & WBSS & FH & LpKY97 & PL3-1 & PH42 & Guy11 & P131 & Y34 & Arcadia \\
\hline WBKY & 3,785 & 2,521 & 3,228 & 3,196 & 1,395 & 1,384 & 90 & 4,894 & 7,280 & 7,565 & 7,533 & 7,774 \\
\hline B2 & $\ldots$ & 2,300 & 2,145 & 2,467 & 3,699 & 3,688 & 3,835 & 6,335 & 7,528 & 7,755 & 7,732 & 8,109 \\
\hline Br130 & $\ldots$ & $\ldots$ & 1,934 & 1,846 & 2,270 & 2,257 & 2,546 & 5,337 & 7,155 & 7,259 & 7,222 & 7,570 \\
\hline WHTQ & $\ldots$ & $\ldots$ & $\ldots$ & 757 & 2,980 & 2,994 & 3,292 & 5,689 & 7,739 & 7,964 & 7,905 & 8,275 \\
\hline WBSS & $\ldots$ & $\ldots$ & $\ldots$ & $\ldots$ & 3,010 & 3,024 & 3,308 & 5,621 & 7,552 & 7,716 & 7,689 & 7,923 \\
\hline FH & $\ldots$ & $\ldots$ & $\ldots$ & $\ldots$ & $\ldots$ & 82 & 1,416 & 4,968 & 7,532 & 7,773 & 7,756 & 8,097 \\
\hline LpKY97 & $\ldots$ & $\ldots$ & $\ldots$ & $\ldots$ & $\ldots$ & $\ldots$ & 1,416 & 4,921 & 7,538 & 7,782 & 7,737 & 8,034 \\
\hline PL3-1 & $\ldots$ & $\ldots$ & $\ldots$ & $\ldots$ & $\ldots$ & $\ldots$ & $\ldots$ & 4,927 & 7,418 & 7,666 & 7,619 & 7,943 \\
\hline PH42 & $\ldots$ & $\ldots$ & $\ldots$ & $\ldots$ & $\ldots$ & $\ldots$ & $\ldots$ & $\ldots$ & 8,919 & 9,154 & 9,121 & 9,441 \\
\hline Guy11 & $\ldots$ & $\ldots$ & $\ldots$ & $\ldots$ & $\ldots$ & $\ldots$ & $\ldots$ & $\ldots$ & $\ldots$ & 431 & 450 & 2,840 \\
\hline P131 & $\ldots$ & $\ldots$ & $\ldots$ & $\ldots$ & $\ldots$ & $\ldots$ & $\ldots$ & $\ldots$ & $\ldots$ & $\ldots$ & 228 & 2,886 \\
\hline Y34 & $\ldots$ & $\ldots$ & $\ldots$ & $\ldots$ & $\ldots$ & $\ldots$ & $\ldots$ & $\ldots$ & $\ldots$ & $\ldots$ & $\ldots$ & 2,884 \\
\hline
\end{tabular}

a Distances are represented in single-nucleotide polymorphism per megabase of alignable, single-copy DNA. Bold indicates the most closely related strains and italics indicate the next most closely related strains.

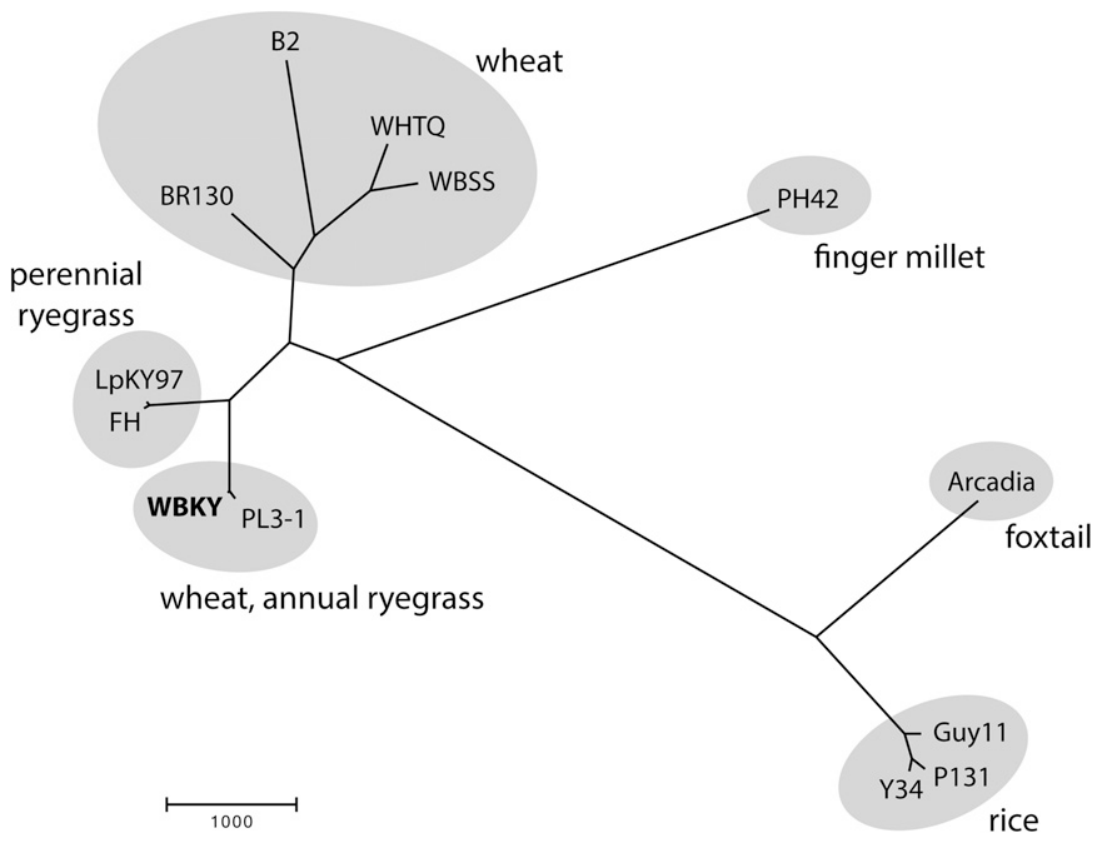

Fig. 3. Neighbor joining tree showing relationship of the Kentucky wheat blast strain to other Magnaporthe oryzae isolates. Repeat-masked genome sequences were aligned using blastn and genetic distances were calculated using the SNP_counts perl script. A neighbor-joining tree was constructed using MEGA v. 6.06 (Tamura et al. 2013). Genetic distances are represented as percent sequence divergence in uniquely alignable DNA regions. Note: it is not possible to perform bootstrapping on pairwise distance data. 
Pathogenicity testing of the Kentucky wheat blast isolate. To confirm that WBKY11-15 is a genuine pathogen of wheat, conidial suspensions were sprayed on spikes of susceptible Cavalier. As a control, equivalent spore suspensions of a bona fide wheat pathogen (T25) collected in Brazil in 1988 were included. Based on the percentages of infected spikelets, there was no significant difference in the levels of disease produced by four of five different conidial concentrations. Probability estimates $\left(\operatorname{Pr}\left[\right.\right.$ datal $\left.\left.\mathrm{H}^{0}\right]\right)$ were $0.414,0.155,0.521$, and 0.683 for $1 \times 10^{3}, 5 \times 10^{3}, 1 \times 10^{4}$, and $1 \times 10^{5}$ conidia $/ \mathrm{ml}$, respectively. No infection was observed in the water-inoculated controls.

Upon discovery that WBKY11-15 was genetically similar to a Lolium-infecting strain, we next inoculated spikes of Cavalier with a selection of strains from perennial ryegrass, annual ryegrass, and other endemic isolates from St. Augustinegrass and Italian foxtail millet. WBKY11-15 was again consistently able to infect wheat, causing disease in $83.7 \%$ of inoculated spikes (standard deviation $29 \%$; Table 3 ). In the same trials, the positive control isolate, B2, caused disease in $100 \%$ of spikes. Importantly, the two annual ryegrass pathogens and five GLS pathogens that were tested also caused spike infections with high incidence, although the level of disease was significantly lower for all but one isolate (PgPA05T-01; Table 3). There was no significant difference in infection capability among the Lolium isolates $(P>0.13)$. Isolates from Italian foxtail millet ( $S$. italica) and St. Augustinegrass (Stenotaphrum secundatum) were unable to infect wheat heads (Table 3). In all cases where disease occurred, M. oryzae was successfully isolated from lesions, thereby completing Koch's postulates.

Weather-based modeling of wheat blast for Princeton in spring 2011. Given that isolates capable of infecting wheat had existed in the United States for many years prior to the first discovery of $M$. oryzae on wheat, we were curious as to whether the Kentucky climate might have been unusually conducive to wheat blast in spring 2011. To test this idea, we utilized a predictive model (Bavaresco et al. 2015) (https://github.com/jlbavaresco/brusoneModel) to perform a retrospective study using historical weather data. In Brazil, wheat blast epidemics are normally associated with periods where the model calculates cumulative hours of conidium production (chcp) at heading of 40 to 50 and when the calculated inoculum potential (IP) is greater than 30 (Fig. 4A). In early 2011, when the Kentucky wheat crop was heading, conditions throughout the state were far from reaching these thresholds (chcp $<9$ and IP $<7$; Table 4). However, in some regions, including Princeton, the model predicted that favorable conditions had started to accumulate and were on the increase when the outbreak started (Fig. 4B). Thus, it is reasonable to suppose that significant inoculum was already present at heading time. When the model was applied to the analysis of weather data for prior years, the values for chcp and IP were well below those determined for 2011 (Table 4; note that 2008 was the earliest year for which relevant data were available).

\section{Discussion}

When classical disease diagnostic methods identified $M$. oryzae as the probable organism causing head disease in a single wheat plant at the UKREC, this discovery had serious and potentially far-reaching implications. The primary concern was that this event signaled the arrival, on U.S. soil, of a deadly $M$. oryzae wheat blast strain from South America. Therefore, as soon as the presence of $M$. oryzae was confirmed from the diseased head sample, an intensive effort was made to scout for more wheat blast in the affected and neighboring plots. However, by the time wheat blast had been confirmed by PCR, FHB was well established and this complicated the scouting efforts. Among 20 suspect spikes that were collected, all turned out to have FHB infections with no obvious signs of blast. Although these data do not rule out additional blast occurrences, they indicate that further disease was below detectable levels. As such, the 2011 incident was fortunate in the sense that it resulted in minimal damage yet alerted the community to the possibility of more serious U.S. wheat blast outbreaks occurring in the near future.

Had the exotic form of the wheat blast pathogen made its way into the U.S. wheat production system, this not only could have heralded impending crop losses but also could have affected wheat export and trade. Therefore, it was imperative that we make a rapid molecular diagnosis of the pathogen and determine its probable origin. Wheat blast usually causes widespread, devastating, and almost synchronous damage upon its initial appearance in the field (Cruz et al. 2012). Based on the limited nature of the Kentucky wheat blast find, we suspected that this was an isolated case due to opportunistic infection by an endemic M. oryzae or M. grisea strain. Previous research indicated that $M$. oryzae strains causing wheat blast are most closely related to strains causing gray leaf spot on perennial ryegrass (Couch et al. 2005; Farman 2002; Tosa et al. 2004; Viji et al. 2001). For this reason, we focused our efforts on comparing the suspect isolate with bona fide wheat blast strains from South America and Lolium-infecting strains from the United States.

The only molecular markers that were available at the time of the outbreak provided an equivocal answer as to the origin of the suspect isolate. This conundrum was resolved by analyzing wholegenome sequence data, which provided convincing evidence that WBKY11-15 is very closely related to PL3-1, an isolate collected in 2002 from L. multiflorum (annual ryegrass) growing in Pulaski County, KY. As an aside, it should be noted that the SNP density between these two strains ( $90 \mathrm{SNPs} / \mathrm{Mb}$ ) is similar to that obtained from independent assemblies of a single fungal strain based on 454 versus Illumina sequencing (approximately $20 \mathrm{SNPs} / \mathrm{Mb}$; data not shown). This extremely close similarity between WBKY11-15 and PL3-1 is most consistent with the hypothesis that the Kentucky wheat blast case resulted from a "host jump" by a member of an endemic pathogen population, as opposed to the arrival of an exotic strain. Having said this, it is important to mention that more recent genomic sequencing studies have identified South American wheat blast strains that group with MoL isolates (unpublished). Although this does not alter the conclusion of the present study - namely, that WBKY11-15 most likely arose from an endemic population-it does show that there is extensive genetic overlap between the South American MoT and U.S. MoL populations.

Table 3. Disease incidence scores following wheat head inoculations

\begin{tabular}{|c|c|c|c|c|c|c|}
\hline Isolate & Host & Heads $(n)^{\mathbf{a}}$ & Infected $(\%)^{\mathbf{b}}$ & $\mathbf{S D}^{\mathbf{c}}$ & $\boldsymbol{P}$ & Recovered $^{d}$ \\
\hline B2 & Triticum aestivum & 9 & 100.00 & 0.00 & $\ldots$ & Yes \\
\hline WBKY11-15 & T. aestivum & 7 & 83.71 & 28.80 & 0.046 & Yes \\
\hline PL2-1 & Lolium multiflorum & 9 & 75.11 & 28.37 & 0.018 & Yes \\
\hline PL3-1 & L. multiflorum & 9 & 57.11 & 42.70 & 0.008 & Yes \\
\hline FH & L. perenne & 9 & 80.54 & 28.81 & 0.06 & Yes \\
\hline PgPA33B-01 & L. perenne & 8 & 85.08 & 13.68 & 0.013 & Yes \\
\hline PgPA05T-01 & L. perenne & 9 & 93.84 & 12.23 & 0.06 & Yes \\
\hline PgPA33B-06 & L. perenne & 8 & 89.42 & 12.14 & 0.02 & Yes \\
\hline PgPA18C-04 & L. perenne & 8 & 84.66 & 25.37 & 0.09 & No \\
\hline UFO822 & Stenotaphrum secundatum & 3 & 0.00 & 0.00 & $\ldots$ & No \\
\hline S-4 & Setaria italica & 3 & 0.00 & 0.00 & $\ldots$ & No \\
\hline
\end{tabular}

\footnotetext{
${ }^{\text {a }}$ Heads inoculated.

${ }^{\mathrm{b}}$ Spikelets infected.

c Standard deviation.

${ }^{\mathrm{d}}$ Magnaporthe oryzae recovered.
} 
The discovery that WBKY11-15 is most closely related to endemic fungal strains goes a long way toward assuaging collateral concerns associated with the first U.S. case of M. oryzae on wheat. First, the genetic characterization of the suspect isolate indicated that it was unlikely to be an exotic introduction because it was most closely related to an M. oryzae strain that was collected in 2001 from diseased annual ryegrass in Pulaski County, KY (approximately 225 miles from the UKREC). Second, infectivity tests showed that, although WBKY11-15 was certainly capable of infecting wheat, it was consistently less aggressive than the South American wheat blast
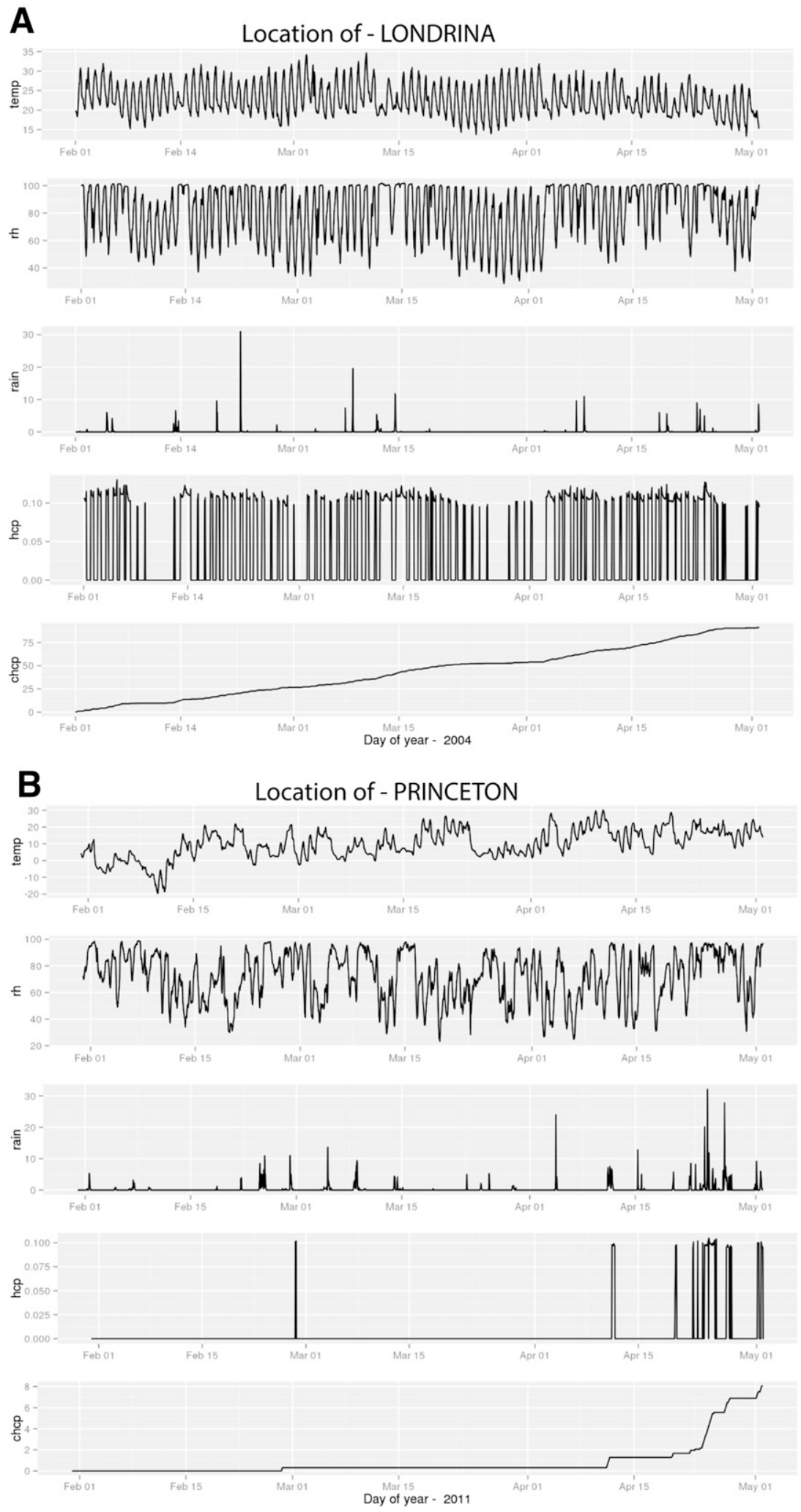

Fig. 4. SMART-SIM wheat blast predictive model. Shown are screenshots of the calculated risk factors for A, wheat blast in Londrina, Paraña State, Brazil, 2004 (an epidemic year) and $\mathbf{B}$, wheat blast in Princeton, KY, 2011. Values are temp = temperature in Celsius, $r h=$ relative humidity, rain $=$ precipitation in $\mathrm{mm}$, hcp $=$ hours favorable for conidium production, and chcp = cumulative hours favorable for conidium production. 
strain T25. Moreover, we found that gray leaf spot isolates collected from U.S. perennial ryegrass up to 16 years prior to the Kentucky event were capable of causing head blast at disease levels similar to WBKY11-15. Thus, it appears that endemic strains with the potential to infect wheat have been present in the United States for at least 16 years without causing severe disease outbreaks.

Given that $M$. oryzae strains capable of causing wheat blast have been in the United States for several years, the question arises as to why the disease has never been previously observed. One possibility is that low levels of blast have occurred on a regular basis but are usually masked by concurrent FHB infections. The symptomatology of the two diseases is very similar, with the only difference being that Fusarium-infected heads often take on a pale salmon coloration, whereas blasted heads remain a bleached yellow or white.

Another probable factor limiting the occurrence of major U.S. wheat blast epidemics is climate. Although far from conclusive, our retrospective modeling results are certainly consistent with the idea that the potential for wheat blast is usually limited by the harvesting of wheat before the development of favorable climatic conditions for inoculum production. Kentucky winter wheat typically heads in late April to early May and is harvested mid-June to early July. Typically, $M$. oryzae and the related fungus $M$. grisea are not seen on weedy grasses and turf grasses in the state until late July and August (M. Farman, personal observations). Thus, the wheat crop has normally been harvested long before Magnaporthe-related disease epidemics get established. In the northern United States, where wheat is harvested later in the summer or fall, $M$. oryzae diseases have not been reported on perennial ryegrass or annual ryegrass, suggesting that the climate is not conducive to epidemics by $M$. oryzae.

Fortunately, the Kentucky wheat blast failed to develop beyond a single affected plant and there have been no signs of wheat blast at UKREC since the 2011 incident. Nevertheless, this event, and our recent discovery of Brazilian wheat blast strains that group with the MoL pathotype (unpublished), alert us to the possibility of Loliumadapted populations causing future wheat blast epidemics in the United States, especially in the face of possible climate change. This,

Table 4. Cumulative hours favorable for conidium production (chcp) and inoculum potential (IP) in Princeton, KY and surrounding counties in 2008 to $2011^{\mathrm{a}}$

\begin{tabular}{lll}
\hline Place (county), year & chcp & IP \\
\hline Princeton (Caldwell) & nd & nd \\
2008 & 2.5 & 1.2 \\
2009 & 2.8 & 0.8 \\
2010 & 8.1 & 6.6 \\
2011 & & \\
Benton (Marshall) & nd & nd \\
2008 & nd & nd \\
2009 & 2.2 & 0.9 \\
2010 & 8.0 & 6.4 \\
2011 & & \\
Hopkinsville (Christian) & 1.0 & nd \\
2008 & 2.7 & 1.1 \\
2009 & 3.1 & 1.1 \\
2010 & 4.4 & 4.3 \\
2011 & & \\
Marion (Crittenden) & nd & nd \\
2008 & nd & nd \\
2009 & 1.4 & 0.8 \\
2010 & 6.6 & 5.7 \\
2011 & & \\
Neighboring counties & & $0.1,0$ \\
Bowling Green $(2008,2009)$ & $0.2,0$ & 0,0 \\
Henderson (2008, 2009) & 0,0 & $0.2,1.1$ \\
Owensboro (2008, 2009) & $0.2,1.7$ & $0,0.3$ \\
Paducah (2008, 2009) & $0,0.59$ & \\
\hline
\end{tabular}

\footnotetext{
${ }^{\text {a }}$ Results on 1 May of each year surveyed; nd = no data.

${ }^{\mathrm{b}}$ Data for additional neighboring counties provided to make up for missing data points in the target counties for years 2008 and 2009
}

together with the 2016 Asian wheat blast outbreak that was caused by a highly aggressive South American MoT strain (Malaker et al. 2016), illustrates the importance of incorporating blast resistance into U.S. wheat cultivars as part of an anticipatory breeding program.

\section{Acknowledgments}

We thank A. Ruck and M. Heist for their technical assistance and the Kentucky Climate Center at Western Kentucky University for assistance in acquiring weather data from the Kentucky Mesonet system (http://www.kymesonet.org). This project is supported by Agriculture and Food Research Initiative Competitive Grant numbers 2009-55605-05201 and 2013-68004-20378 from the USDA National Institute of Food and Agriculture. Additional support came from USDA special grant 201034457-21269.

\section{Literature Cited}

Arai, N., and Yoshino, R. 1987. Studies on the sporulation of rice blast fungus. Relation between sporulation and temperature. Ann. Phytopathol. Jpn. 53:371-372.

Barea, G., and Toledo, J. 1996. Identificación y zonificación de Pyricularia o brusone (Pyricularia oryzae) en el cutivo de trigo en el departamento de Santa Cruz. Centro de Investigación Agrícola Tropical, Santa Cruz de la Sierra, Bolivia.

Bavaresco, J. L. B., Fernandes, J. M. C., Pavan, W., and Lazzaretti, A. T. 2015. SMARTSIM, an integrative modeling approach: Risk mapping assessment of wheat blast. Poster Abstract: Conference on Advancing Pest and Disease Modeling, UF/IFAS, Gainesville, FL.

Cabrera, M., and Gutiérrez, S. 2007. Primer registro de Pyricularia grisea en cultivos de trigo del NE de Argentina. Depto. Protección Vegetal, Facultad de Ciencias Agrarias, Universidad Nacional del Nordeste, Corrientes/ Resistencia, Argentina

Couch, B. C., Fudal, I., Lebrun, M. H., Tharreau, D., Valent, B., van Kim, P., Notteghem, J. L., and Kohn, L. M. 2005. Origins of host-specific populations of the blast pathogen Magnaporthe oryzae in crop domestication with subsequent expansion of pandemic clones on rice and weeds of rice. Genetics 170:613-630.

Cruz, C. D., Bockus, W. W., Stack, J. P., Tang, X., Valent, B., Pedley, K. F., and Peterson, G. L. 2012. Preliminary assessment of resistance among U.S. wheat cultivars to the Triticum pathotype of Magnaporthe oryzae. Plant Dis. 96:1501-1505.

Dos Anjos, J., Da Silva, D., Charchar, M., and Rodrigues, G. 1996. Ocorrência de brusone (Pyricularia grisea) em trigo e centeio na região dos cerrados do Brasil Central. Pesqui. Agropecu. Bras. 31:79-82.

Farman, M. L. 2002. Pyricularia grisea isolates causing gray leaf spot on perennial ryegrass (Lolium perenne) in the United States: Relationship to P. grisea isolates from other host plants. Phytopathology 92:245-254.

Gilles, A., Meglecz, E., Pech, N., Ferreira, S., Malausa, T., and Martin, J. F. 2011 Accuracy and quality assessment of 454 GS-FLX Titanium pyrosequencing. BMC Genomics 12:245.

Goff, S. A., Vaughn, M., McKay, S., Lyons, E., Stapleton, A. E., Gessler, D. Matasci, N., Wang, L., Hanlon, M., Lenards, A., Muir, A., Merchant, N., Lowry, S., Mock, S., Helmke, M., Kubach, A., Narro, M., Hopkins, N., Micklos, D., Hilgert, U., Gonzales, M., Jordan, C., Skidmore, E., Dooley, R., Cazes, J., McLay, R., Lu, Z., Pasternak, S., Koesterke, L., Piel, W. H., Grene, R., Noutsos, C., Gendler, K., Feng, X., Tang, C., Lent, M., Kim, S. J., Kvilekval, K., Manjunath, B. S., Tannen, V., Stamatakis, A., Sanderson, M., Welch, S. M., Cranston, K. A., Soltis, P., Soltis, D., O'Meara, B., Ane, C., Brutnell, T., Kleibenstein, D. J., White, J. W., Leebens-Mack, J., Donoghue, M. J., Spalding, E. P., Vision, T. J., Myers, C. R., Lowenthal, D., Enquist, B. J., Boyle, B., Akoglu, A., Andrews, G., Ram, S., Ware, D., Stein, L., and Stanzione, D. 2011. The iPlant Collaborative: Cyberinfrastructure for plant biology. Front. Plant Sci. 2. doi:10.3389/fpls.2011.00034

Goulart, A., and Paiva, F. 2000. Perdas no rendimiento de grãos de trigo causada por Pyricularia grisea, nos anos de 1991 e 1992, no Mato Grosso do Sul. Summa Phytopathol. 26:279-282.

Goulart, A., Paiva, F., and Mesquita, A. 1990. Ocorrência da brusone (Pyricularia oryzae) do trigo (Triticum aestivum) em Matto Grosso do Sul. Fitopatol. Bras. 15:112-114.

Goulart, A., Paiva, F., and Mesquita, N. 1992. Perdas en trigo (Triticum aestivum) causadas por Pyricularia oryzae. Fitopatol. Bras. 17:115-117.

Igarashi, S. 1990. Update on wheat blast (Pyricularia oryzae) in Brazil. Pages 480-483 in: Proc. Int. Conf. Wheat Nontrad. Warm Areas. D. Saunders, ed. CIMMYT, Mexico DF, Mexico.

Igarashi, S., Utimada, C., Igarashi, L., Kazuma, A., and Lopes, R. 1986. Pyricularia sp. em trigo. I. Ocorrência de Pyricularia sp. no Estado do Paranà. Fitopatol. Bras. 11 351-352.

Kim, K. R. 2000. Weather-driven models for rice leaf blast and their implementation to forecast disease development on the near real-time basis. Ph.D. thesis, Seoul National University, Suwon, Korea.

Kohli, M., Mehta, Y., Guzman, E., Viedma, L., and Cubilla, L. 2011. Pyricularia blast-A threat to wheat cultivation. Czech J. Genet. Plant Breed. 47:S130-S134.

Leung, H., Borromeo, E. S., Bernado, M. A., and Notteghem, J. L. 1988. Genetic analysis of virulence in the rice blast fungus Magnaporthe grisea. Phytopathology 78:1227-1233. 
Maciel, J. L., Ceresini, P. C., Castroagudin, V. L., Zala, M., Kema, G. H., and McDonald, B. A. 2014. Population structure and pathotype diversity of the wheat blast pathogen Magnaporthe oryzae 25 years after its emergence in Brazil. Phytopathology 104:95-107.

Malaker, P. K., Barma, N., Tiwari, T. P., Collis, W. J., Duveiller, E., Singh, P. K., Joshi, A. K., Singh, R., Braun, H.-J., Peterson, G. P., Pedley, K. F., Farman, M. L., and Valent, B. 2016. First report of wheat blast caused by Magnaporthe oryzae pathotype Triticum in Bangladesh. Plant Dis. 100:2330.

Melching, J. S., Bromfield, K. R., and Kingsolver, C. H. 1983. The plant pathogen containment facility at Frederick, Maryland. Plant Dis. 67:717-722.

Ou, S. H. 1985. Rice Diseases. Commonwealth Mycological Institute, Surrey, UK.

Picinini, E., and Fernandes, J. 1990. Ocorrência da brusone (Pyricularia oryzae) em lavouras comerciais de trigo (Triticum aestuvum) no Estado do Rio Grande do Sul. Fitopatol. Bras. 15:83-84.

Starnes, J. H., Thornbury, D. W., Novikova, O. S., Rehmeyer, C. J., and Farman, M. L. 2012. Telomere-targeted retrotransposons in the rice blast fungus Magnaporthe oryzae: Agents of telomere instability. Genetics 191:389-406.

Tamura, K., Stecher, G., Peterson, D., Filipski, A., and Kumar, S. 2013. MEGA6: Molecular Evolutionary Genetics Analysis version 6.0. Mol. Biol. Evol. 30:2725-2729.

Tosa, Y., Hirata, K., Tamba, H., Nakagawa, S., Chuma, I., Isobe, C., Osue, J., Urashima, A. S., Don, L. D., Kusaba, M., Nakayashiki, H., Tanaka, A., Tani, T., Mori, N., and Mayama, S. 2004. Genetic constitution and pathogenicity of Lolium isolates of Magnaporthe oryzae in comparison with host speciesspecific pathotypes of the blast fungus. Phytopathology 94:454-462.

Tosa, Y., Uddin, W., Viji, G., Kang, S., and Mayama, S. 2007. Comparative genetic analysis of Magnaporthe oryzae isolates causing gray leaf spot of perennial ryegrass turf in the United States and Japan. Plant Dis. 91:517-524.
Urashima, A. S., Grosso, C. R. F., Stabili, A., and Merola-Bottan, J. H. 2009. Effect of Magnaporthe grisea on seed germination, yield and quality of wheat. Pages 267-277 in: Advances in Genetics, Genomics and Control of Rice Blast Disease. G.-L. Wang and B. Valent, eds. Springer Science+ Business Media B.V., New York.

Urashima, A. S., Hashimoto, Y., Don, L. D., Kusaba, M., Tosa, Y., Nakayashiki, H., and Mayama, S. 1999. Molecular analysis of the wheat blast population in Brazil with a homolog of the retrotransposon MGR583. Ann. Phytopathol. Soc. Jpn. 65:429-436.

Valent, B., Crawford, M. S., Weaver, C. G., and Chumley, F. G. 1986. Genetic studies of fertility and pathogenicity in Magnaporthe grisea. Iowa State J. Res. 60:569-594.

Viedma, L. 2005. Wheat blast occurrence in Paraguay. (Abstr.) Phytopathology 95:S152.

Viji, G., Wu, B., Kang, S., and Uddin, W. 2001. Pyricularia grisea causing gray leaf spot of perennial ryegrass turf: Population structure and host specificity. Plant Dis. 85:817-826.

Vincelli, P., Dixon, E., and Farman, M. 2008. Susceptibility of selected cultivars of forage grasses to Magnaporthe oryzae isolates from annual ryegrass and relatedness of the pathogen to strains from other grasses. Forage Grazinglands 6. Online publication. Plant Management Network. doi:10.1094/FG-2008 0226-01-RS

Xue, M., Yang, J., Li, Z., Hu, S., Yao, N., Dean, R. A., Zhao, W., Shen, M., Zhang, H., Li, C., Liu, L., Cao, L., Xu, X., Xing, Y., Hsiang, T., Zhang, Z., Xu, J.-R., and Peng, J.-L. 2012. Comparative analysis of the genomes of two field isolates of the rice blast fungus Magnaporthe oryzae. PLoS Genet. 8:e1002869. 